\title{
WIBAWA IJTIMA ULAMA
}

Oleh Shohibul Anshor Siregar

ljtima Ulama (IU) yang terselenggara tanggal 27 Juli 2019 itu kurang lebih adalah upaya merumuskan pokok pikiran ijtihadi bersifat rekomendatif. Secara otoritatif para ulama memosisikannya sebagai ijtihad memberi solusi untuk Indonesia yang maslahat melallU suksesi (pilpres) 2019.

Sebagaimana diketahui, hasil IU yang diumumkan oleh Yusuf Martak selaku penggagas (di Jakarta) itu merekomendasikan 4 hal. Pertama, Prabowo Subianto sebagai Capres RI pada Pilpres 2019. Kedua, cawapres pendamping Prabowo Subianto adalah AlHabib Salim Segaf Al-Jufri atau Ustadz Abdul Somad Batubara. Ketiga, IU memberi nama bagi pengusung gagasan yang mereka tawarkan, yakni "Partai Koalisi Keumatan". Keempat, forum IU juga menyatakan mandat kepada Dewan Pembina GNPF Ulama Habib Rizieq Shihab untuk mengambil keputusan atas dinamika yang berkembang dalam proses Pilpres 2019.

Melihat hasilnya, IU menunjukkan bahwa kalimatun sawa (kata sepakat) lebih mudah diperoleh untuk nama Prabowo Subianto sebagai Capres. Terbukti untuk menjadi Cawapres pendamping direkomendasikan dua nama. IU benar-benar mempertimbangkan faktor kepartaian dan kefiguran serta ingin mengkombinasikannya tidak saja atas dasar pertimbangan kapabilitas dan elektabilitas serta keterwakilan. Karena itu nama-nama yang dibahas tidak hanya ulama di luar partai seperti Habib Rizieq Shihab, Al-Habib Salim Segaf Al-Jufri dan Ustadz Abdul Somad Batubara, tetapi juga figur dari partai atau yang memiliki pengalaman kepartaian (Prabowo Subianto, Zulkifli Hasan, Yusril Ihza Mahendra, dan Tuan Guru Bajang atau Zainul Majdi).

IU juga sangat memerhitungkan kewibawaan seorang ulama Indonesia yang kini terpaksa behijrah ke luar negeri karena diperlakukan buruk secara hukum (Habib Rizieq Shihab) di Indonesia.

Tak begitu disadari oleh halayak tertentu bahwa salah satu fungsi IU ini ialah tantangan terbuka dan elegan kepada sekularisasi yang melanda Indonesia dan yang menyebabkan proses ketersingkiran posisi umat Islam yang terus-menerus di baik di dalam kancah politik maupun perekonomian. Indonesia ternyata begitu cepat lupa bahwa Pancasila dan konstitusinya yang begitu kental dengan gagasan anti sekularisme yang dipengaruhi oleh ajaran Islam. Indonesia bisa begtu cepat lupa bahwa tokoh-tokoh besar dalam sejarah Indonesia seperti 3 mantan Presiden Republik Indonesia (Sjafruddin Prawira Negara, Assaat, dan Gus Dur), mantan Perdana Menteri Mohammad Natsir, Mohammad Roem dan lain-lain, adalah negarawan yang religious bahkan berkategori ulama yang otoritatif dari segi keilmuan dan kemampuannya. 
Singkatnya, IU ini begitu tegas memesankan bahwa sesiapa yang mengatakan agama harus dipisahkan dengan politik, di sini benar-benar dianggap sama sekali tak pernah faham tentang agama. Ini bukanlah keluhan khas Islam saja, karena di dalam An Antisecularist Manifesto (Ashis Nandy, India International Centre Quarterly Vol. 22, No. 1, Seculrism in Crisis, Spring 1995, pp. 35-64) Mahatma Gandi juga dikutip pernah mengatakan sesiapa yang memisahkan antara agama dan politik menunjukkan ketidak-fahamannya kepada keduanya.

Pesan moral yang kuat dari IU kini sudah harus mulai disadari bahwa ulama itu tak mesti dianggap pas hanya dipojokkan pada sudut kecil kehidupan yang amat khas katakanlah (maaf) tukang doa sebagaimana terjadi selama ini. Meski begitu tak semua yang berjuluk ulama berkapasitas komplit seperti para negarawan muslim Indonesia yang disebut di atas.

Definisi ulama pun rasanya kini sangat membutuhkan tinjauan, bahwa tanpa serban dan tanpa privelege kultural yang lazim lainnya seseorang juga dapat menjadi ulama yang capable dan tafaqquh fiddin wa tafaqquh finnas (taat kepada agama dan setia kepada rakyat).

Menanggapi hasil IU berbagai pendapat muncul dan tak selamanya sepandangan, bahkan dari afiliasi yang sama. Misalnya, tokoh Muda NU Zuhairi Misrwai menyebut IU tidak mempunyai legitimasi MUI dan menurutnya partisan alias memihak kepada kelompok oposisi ataupun kelompok lainya. Hal itu dinyatakannya dalam sebuah diskusi bertema "Ijtima Ulama: Politik Agama atau Politisasi Agama" yang diselenggarakan Lembaga Penelitian Agama dan Sosial (Leppas) di Jakarta (Rabu,8/8/18).

Ketika dua nama (Al-Habib Salim Segaf Al-Jufri dan Ustadz Abdul Somad Batubara) yang direkomendasikan IU akhirnya tak satu pun yang dipasangkan untuk Prabowo Subianto untuk pilpres 2019, muncul anggapan bahwa hasil IU sudah disepelekan. Saat berkunjung ke kantor PPP (Jum'at, 10/8/18) KH Ma'ruf Amin mengkapitalisasi masalah ini dengan mengatakan "Sebelah sono ngomongnya menghormati ulama tapi usul IU enggak didengerin. Malah wakilnya bukan ulama”. Ketum PPP Romahurmuzy pada hari yang sama juga berucap senada saat berada di kantor KPU: "Publik bisa menilai siapa yang bersama dan yang meninggalkan ulama".

Tetapi yang menarik adalah bahwa kedua ucapan itu sama-sama memberi pengakuan yang jujur atas pentingnya IU yang merekomendasikan Prabowo Subianto sebagai Capres dan Al-Habib Salim Segaf Al-Jufri atau Ustadz Abdul Somad Batubara sebagai pasangannya. Hanya saja tidak sesuai dengan keinginan pencapresan Joko Widodo yang akhirnya dipasangkan dengan KH Ma'ruf Amin.

Tetapi tentulah IU tak hanya perlu dikaji dari sudut ketergangguan kepentingan pencapresan Joko Widodo dan $\mathrm{KH}$ Ma'ruf Amin. Jika pun ada semacam 
misunderstanding pada sesama pendukung $\mathrm{IU}$, selalu terbuka peluang besar untuk mendiskusikan dan tentu sejauh dampak yang muncul hingga saat ini tidak akan sampai menyebabkan perpecahan serius, apalagi jika dibayangkan akan ada yang merapat ke kubu lain. Sulit membayangkan itu.

Dalam malam deklarasi Prabowo-Sandi di kediaman Prabowo Subianto salah seorang tokoh yang direkomendasikan (Al-Habib Salim Segaf Al-Jufri) juga hadir, berpidato dan malah memimpin doa. Sebelumnya dalam pidatonya Prabowo bilang bahwa Ustadz Abdul Somad Batubara juga semestinya hadir dalam deklarasi. Artinya komunikasi sudah berjalan sangat efektif dan hasil yang dicapai cukup kompromistis dan terterima oleh semua pihak.

Jangan lupa bahwa landasan IU itu hanyalah ijtihad politik yang bertujuan maslahat umat. Jika kondisi menghendaki perubahan, fleksibilitasnya dalam kamus fiqh syiyasah juga sangat terbuka. Semua ulama yang ikut andil pasti faham akan hal itu.

Mungkin dengan jernih sekarang bisa diperbandingkan apakah niat menciptakan maslahat umat di balik IU begitu jauh meleset dengan penetapan pasangan PrabowoSandi? IU memilih Prabowo. Jokowi memilih seorang Ulama (KH Ma'ruf Amin). Kurang lebih begitulah yang terjadi.

Interaksi reciprocal (berbalas) ini perlu dilihat secara jernih. Ada yang bilang bahwa rasa cemas yang bersangatan ditutupi dengan pilihan Jokowi terhadap $\mathrm{KH}$ Ma'ruf Amin untuk membendung tuduhan bahwa Joko Widodo itu anti Islam dan untuk menghadapi segenap pengaruh cawapres berlatar belakang ulama yang dipastikan sebagai pendamping Prabowo. Semua kini sudah tahu bahwa saat last minutes paradigma politik identitas itu secara formal tak dihadirkan oleh kubu Prabowo.

Beberapa hal lain yang tak mungkin diabaikan seputar pilpres 2019 yang menghadaphadapkan dua pasangan ini ialah pertama, ada yang bilang politik SARA tak juga akan reda. Jokowi-Ma'ruf akan lebih memikat bagi penduduk mayoritas apalagi di basis komunitas NU, organisasi tempat $\mathrm{KH}$ Ma'ruf Amin selama berkiprah selain di MUI. Kejawaan apa yang "tersisa" dalam hidup Prabowo yang tokoh militer kecuali namanya yang berakhiran "o"? Sandiaga Salahuddin memang bernama akhir Uno. tetapi huruf "o" di belakang nama itu tak diperkaya dengan instrumen kultural yang kuat dan memang ia bukan orang Jawa.

Kedua, ada yang bilang bahwa Joko Widodo dan Prabowo sebetulnya adalah dua tokoh yang sudah terkunci secara popularitas dan elektabilitas oleh kotak diametral pro dan kontra pemilih Indonesia. Jadi sumbangan cawapreslah yang begitu penting dihitung dalam persaingan ini. Maka jika semua rakyat Indonesia sudah puas kinerja Joko Widodo, tak ada aral melintang buatnya melanjutkan kemapanan bersama $\mathrm{KH}$ Ma'ruf Amin 2019-2024. Tetapi faktanya tidak begitu. Lagi pula pewacanaan perubahan yang digerakkan secara kombinatif (Prabowo akan terus mengeritik 
dengan updating data yang menyadarkan pemilih Indonesia seperti dilakukan Mahathir Mohammad selama kampanye Pemilu di Malaysia beberapa bulan lalu, dan Sandiaga akan terus menperjelas arah ekonomi kebangsaan agar adil dan agar tak sesat demi keselamatan Indonesia) tidak dapat dipandang enteng. Lagi pula, tidak ada yang tahu pihak mana sebetulnya yang lebih besar saat ini antara pendukung Jokowi2periode atau 2019GantiPresiden. Semua lembaga survei Indonesia pada dasarnya belum pernah serius memasuki wilayah sensitif ini. Fakta-fakta ini otomatis mendegradasi secara signifikan motif pilihan politik bedasarkan kesukuan.

Ketiga, ada yang bilang permainan ini terletak pada kekuatan relawan di luar partai, karena bagi hampir seluruh partai jauh lebih penting tak tereliminasi pada pileg 2019 ketimbang memiliki presiden dan wakil presiden. Apa boleh buat. Interesting pointnya masih sebatas itu. Malah diperkirakan bahwa pada situasi tertentu di dalam persaingan pemilu serentak 2019, jika konstituen tertentu tak suka capres dukungan partai tertentu, maka partai itu sendiri akan lebih memilih "mencerca" pasangan Capres/Cawapres itu asalkan pilihan kepada partanya aman.

Keempat, ada juga yang bertanya "apa sebetulnya perbedaan mendasar tentang masa depan dan masalahat Indonesia dalam obsesi antara Joko Widodo dan Prabowo dan sebesar apa perkuatan atau pelemahan obsesi itu pada kubu masing-masing dengan kehadiran KH Ma'ruf Amin dan Sandiaga Salahuddin Uno?" Di luar diehard pendukung, orang, terutama kalangan milenial, akan berpikir kritis tentang masa depan Indonesia. Kesadaran mereka telah terpupuk selama pemerintahan Jokowi-JK.

Kelima, ada juga yang bertanya tentang potensi kecurangan dan pihak mana paling mungkin melakukannya serta bagaimana agar jangan juru kumpul dan juru hitung suara (KPU dan jajarannya) yang menentukan pemenang. Ini terkait dengan profesionalitas dan integritas penyelenggara. Banyak catatan tentang ini, yang akhirnya kelompok-kelompok pro demokrasilah, bukan kelompok penggantang kekuasaan, yang paling menentukan pengawasan untuk demokrasi bermartabat.

Ketika belum lama ini sebuah Harian Ibukota menobatkan Ustaz Abdul Somad Batubara menjadi salah seorang tokoh perubahan Indonesia, pertanyaan tentang pengakuan atas peran dan pengaruh tokoh muda ini semakin kritis yang malah semakin terjawab dengan sendirinya dengan kehadirannya memenuhi undangan berbagai pihak di hampir seluruh wilayah tanah air, termasuk di kampus-kampus besar.

IU menolak Jokowi2periode dengan alasan substantif tertentu. Apa iya Ustaz Abdul Somad Batubara yang menghindar dicalonkan mendamping Prabowo akan mengurangi dukungannya karena Sandiaga Salahuddin Uno menggantikan posisinya?

Ustaz Abdul Somad pasti berharap akan ada perubahan besar yang diinginkan khususnya dengan kehadiran bintang terbaru dalam pentas politik Indonesia, Sandiaga 
Salahuddin Uno. Kehadiran orang ini menjanjikan sesuatu yang melampaui paradigma dan orientasi usang yang dipopulerkan selama hampir 5 tahun usia pemerintahan Indonesia.

Penulis dosen FISIP UMSU. Koordinator Umum Pengembangan Basis Sosial Inisiatif \& Swadaya ('nBASIS). 